\title{
The Liberation of Intellectual Capital Through the Natural Evolution of Knowledge Management Systems
}

\author{
Harold M. Campbell* \\ Vaal University of Technology \\ South Africa
}

\section{Introduction}

The research literature on knowledge management (KM) suggests that the valuation and measurement of intellectual capital (IC) is important to business intelligence (BI) and organisational performance. Harnessing the power of $\mathrm{KM}$ requires an effective communication interface which will allow the successful process integration of IC with organisational performance. The seminal research of Nonaka \& Takeuchi (1995), and Brown \& Duguid (1998) among others, established that effective communication of knowledge obtained from an organisational milieu is essential to organisational performance.

For this to happen, the organisation needs to craft an innovative and viable design of its business systems. A business system design (BSD) comprises of a dynamic architecture which is isomorphic across firms in space and time. It is a dense dynamic nexus of social capital, human capital and KM. A firm's IC, is seen as the resultant of its knowledge management network, as posited by von Krogh et al. (2000). Intellectual capital (IC) represents a firm's meta-capability aimed at exploiting opportunities in its continual pursuit of value creation. This process has been one of the most important sources of international competitiveness for some time.

This chapter takes the view that knowledge is shared among organisational members, because, it is connected to the firm's history and experiences, and will soon become the ultimate replacement of other resources. This notion underpins a more general idea that economies of the future will be education-led (Eftekharzadeh (2008)). It means that the capacity to manage knowledge-based intellect will be the critical skill of this era.

If there is one distinguishing feature of the new economy that has developed as a result of powerful forces such as global competition, it is the ascendancy of IC. Competitive, technological, and market pressures have made continuous organisational learning a critical imperative in global strategy effectiveness (Day \& Tate (2006), Hislop (2005), and Campbell (2009)).

Allied to this is the seminal work of Nonaka \& Takeuchi (1995), on knowledge creation, where their theory of knowledge creation identified four categories of knowledge assets. These being:

1. experiential knowledge assets (tacit knowledge, shared through experience);

${ }^{*}$ H. M. Campbell is the HoD: Department of Industrial Engineering, Vaal University of Technology. 
2. conceptual knowledge assets (tacit knowledge, in the form of symbols and language);

3. routine knowledge assets (tacit knowledge, embedded in organisational routines and practices), and

4. systemic knowledge assets (systematized explicit knowledge).

These categories of knowledge are linked to Nonaka \& Takeuchi (1995) modes of knowledge creation and the type of $b a^{1}$ involved. These platforms aid in giving form to the impact of knowledge on innovation processes, in terms of the characteristics of knowledge. There are three such characteristics which influence the innovation dynamics. These are:

- the degree of tacitness;

- the level of complexity, and

- the degree of relatedness between bodies of knowledge being linked together.

These characteristics of knowledge inform the central role of tacit knowledge to innovation processes is well recognised (Gous \& Schutte (2009); Campbell (2005); von Krogh et al. (2000); Campbell (2009); Eftekharzadeh (2008)).

The rest of the chapter is divided into five sections:

1. KM Research concepts - a review of the recent literature which includes definitions of terms as well as a conceptual model for business intelligence, asynchronous groupware, organisational learning, structural capital, and human capital;

2. Research goal - insights from the literature surveyed, a discussion of the innovation processes and network dynamics in terms of the need for intra-organisational collaboration, and the possible types of strategies organisations must devise through external networks, so as to access the requisite knowledge for competitive advantage and $\mathrm{BI}$;

3. Drupal ${ }^{2}$ - highlights of the analysis, limitations of the research and the contribution of the current technologies of content management aimed at managing the integrated knowledge network of organisations,

4. Directorate - a summary of a case study, which describes an iteration of the AR cycle conducted at Directorate, one of the human resources departments of the public service in Botswana, and

5. Concluding remarks - the chapter then points to the way forward for practitioners, and organisations alike.

We now discuss these concepts in greater detail in the next five sections.

\section{2. $\mathrm{KM}$ research}

The most common classification of knowledge in the KM literature may be considered to be that of von Krogh et al. (2000), to date, where an ambiguous distinction between 'explicit knowledge' and 'tacit knowledge' is proffered. Explicit knowledge is codified or articulatable in a formal manner (Nonaka \& Takeuchi (1995)). Explicit knowledge can be easily passed on from one medium to another; that is, it's transferable. 'Tacit knowledge', on the other hand, may be seen as implicit knowledge or hidden knowledge, as opposed to explicit knowledge. Tacit knowledge is personal knowledge, which is bound to the individual.

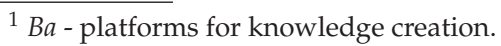

2 Drupal - www.Drupal.org is the official website of Drupal, an open source content management platform.
} 
This is not embedded in some process nor easily transmitted and shared without some systematic effort. The characteristics of tacit knowledge are a subjective view or understanding of a topic, an artefact, an intuition or an internal feeling in the sense of a cultural prejudice, experience, tradition or belief. Tacit knowledge is based on informal metrics, non-standard experience, personal conceptions or convictions. The literature supports this view of tacit knowledge (Nonaka \& Takeuchi (1995), von Krogh et al. (2000), and Campbell (2005)).

Tacit knowledge Explicit knowledge

Future principle

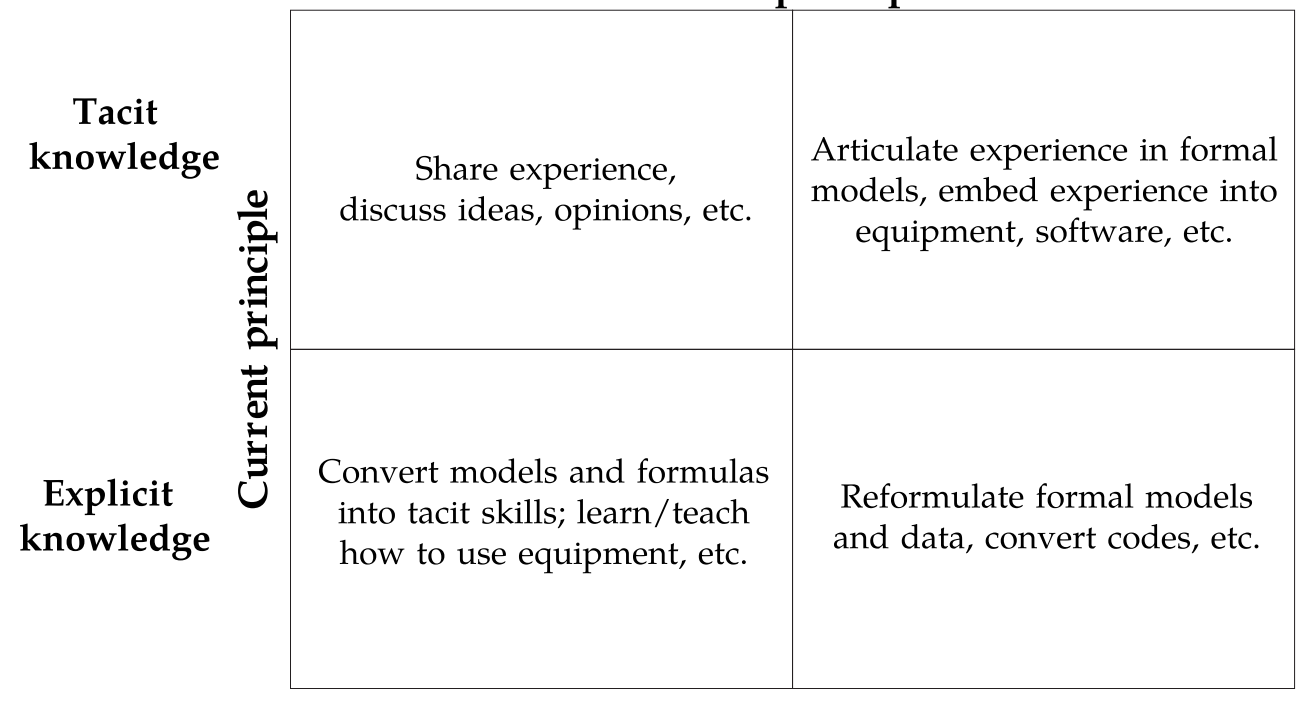

Fig. 1. Modes of knowledge common in the knowledge spiral ( Campbell (2005))

The classification of the foregoing is represented as the modes of knowledge, common in the knowledge spiral, as are illustrated in Fig.1. This figure seeks to explain how active knowledge sharing may be conceived in an organisational milieu. Active knowledge sharing, according to Campbell (2005), subsumes that most organisations will be focusing on one or more of the following four areas: (a) innovation, (b) responsiveness, (c) productivity, and (d) competency, as discussed in Campbell (2005). Consequently, this research takes cognisance of the processes of gathering, searching, filtering, conceptualizing, and transferring of knowledge, at the firm level (Campbell (2005), Hislop (2005), Day \& Tate (2006), and Eftekharzadeh (2008)). As such, aligned to the four areas of active $\mathrm{KM}$, are the following five processes, of $\mathrm{KM}$ :

1. business intelligence;

2. asynchronous groupware;

3. organisational learning;

4. structural capital, and

5. human knowledge,

in which Campbell (2005), discusses how technologies can be used in the context of KM projects. These five KM processes are discussed next. 


\subsection{Business intelligence}

In his study, Campbell (2005) argues that KM effectiveness depends on how one organizes the generation of new knowledge, and the transfer of existing knowledge within the organisation. The views expressed in that study, are supported by recent studies, as they relate to the growing interest in knowledge sharing practices (Davenport \& Prusak (2000), Hislop (2005), and Richard C. Hicks (2007)). It is now commonplace, to find that both scholars and practitioners alike (Sveiby \& Simons (2002)), are robustly discussing the benefits of knowledge transfer and knowledge sharing. Allied also with this is a debate on how organisations can effectively demonstrate their internal knowledge value that is their intellectual capital (Richard C. Hicks (2007)), and of particular relevance is the work of Majchrzak et al. (2004), as it resonates with the idea of knowledge reuse, sharing and conceptualization of meta-knowledge into business intelligence.

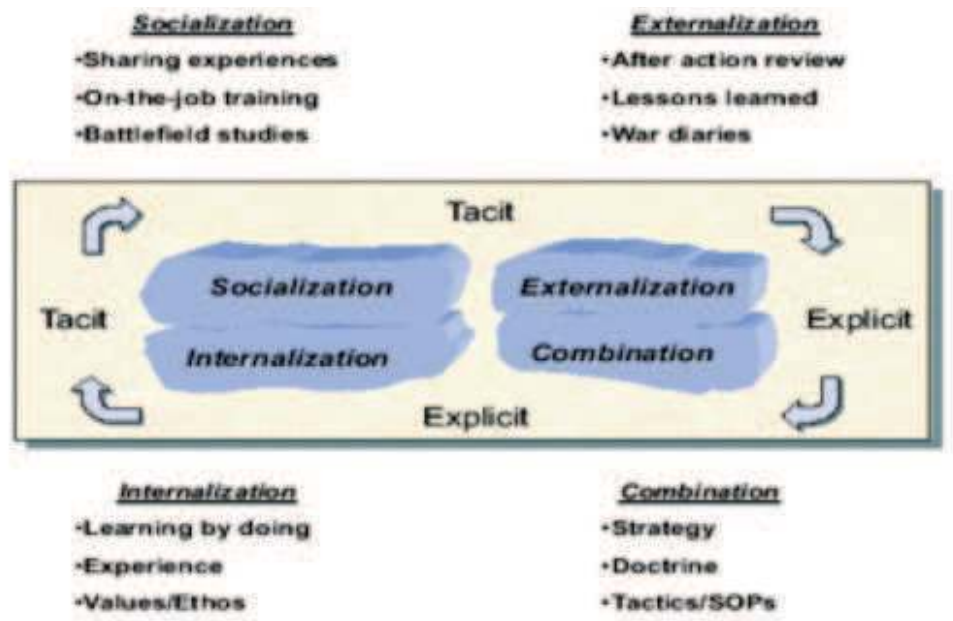

Fig. 2. A framework for knowledge enablement (Nonaka \& Nishiguchi (2001))

In perusing both the literature, and in the study, the researcher found that, one of the most important objectives of KM is to have organisations consolidate their intellectual resources and make them available across organisational boundaries (Martin (2004), and Campbell (2005)). The fact that many of these organisations fail to harness the latent resources of their IC into BI, begs the case for an integrated knowledge network.

\subsection{Asynchronous groupware}

Apart from the development of new knowledge in the enterprise and the acquisition of knowledge from external sources, the knowledge that employees already have should not be ignored. In practice, it is found that most employees find it rather difficult to share their knowledge with each other. The problem is due in part to the nature of the organisational culture, or sometimes, to the modes of operation, in terms of how they synchronize with, or co-ordinate with their KM efforts. If employees espouse the "knowledge is power" mentality, then, there will be a conflict between their personal interests, and the interests of the enterprise in knowledge sharing. An organisational structure, which is favourable for sharing knowledge, must develop a perspective, which does not let this conflict grow out of control. 
Knowledge sharing must be understood as a natural part of the organisation's business, and strategic landscape, in the development of a KM strategy. This is the theme of Fig. 2.

On the part of management, there should be executive commitment to the KM strategy. It cannot be expected that employees will share their knowledge, if structures and mechanisms for this cultural change is not provided, in the organisational basic conditions of operations. The approach will be one that begins with the basic conditions, which provides for the individual employee to have the requisite time for sharing his/her knowledge, and also where necessary, the introduction of non-financial incentive systems as motivation for knowledge sharing.

It is to be understood that knowledge sharing is not only achieved through direct communication. It may take place over a cup of coffee or in a formal session. The concern here, is when it does takes place, where employees enter the codified knowledge in an information system. A substantial aspect for the motivation of employees to use the system depends on the efficiency and the user friendliness of this system. The systems where all participants interact in real-time are called synchronous groupware systems, and performance considerations (such as fast response time) are especially important here. On the other hand, e-mail and messaging systems are examples of asynchronous groupware (van der Aalst \& Kumar (2001)). The metrics governing asynchronous groupware systems will be discussed next.

Campbell (2005), defines groupware as follows:

... Groupware is a generic term for computer-based systems which are particularly used to support groups of people engaged in common tasks in organisations. Typically, these groups are small; businesses oriented, and have relevant tasks with definite deadlines [cf. Fig. 1]. There are several taxonomies for groupware. The two most commonly accepted are the application-level taxonomy, based on the main functions the system provides to its users; and the time-space taxonomy, based on the users' temporal and physical distribution while interacting through the system.

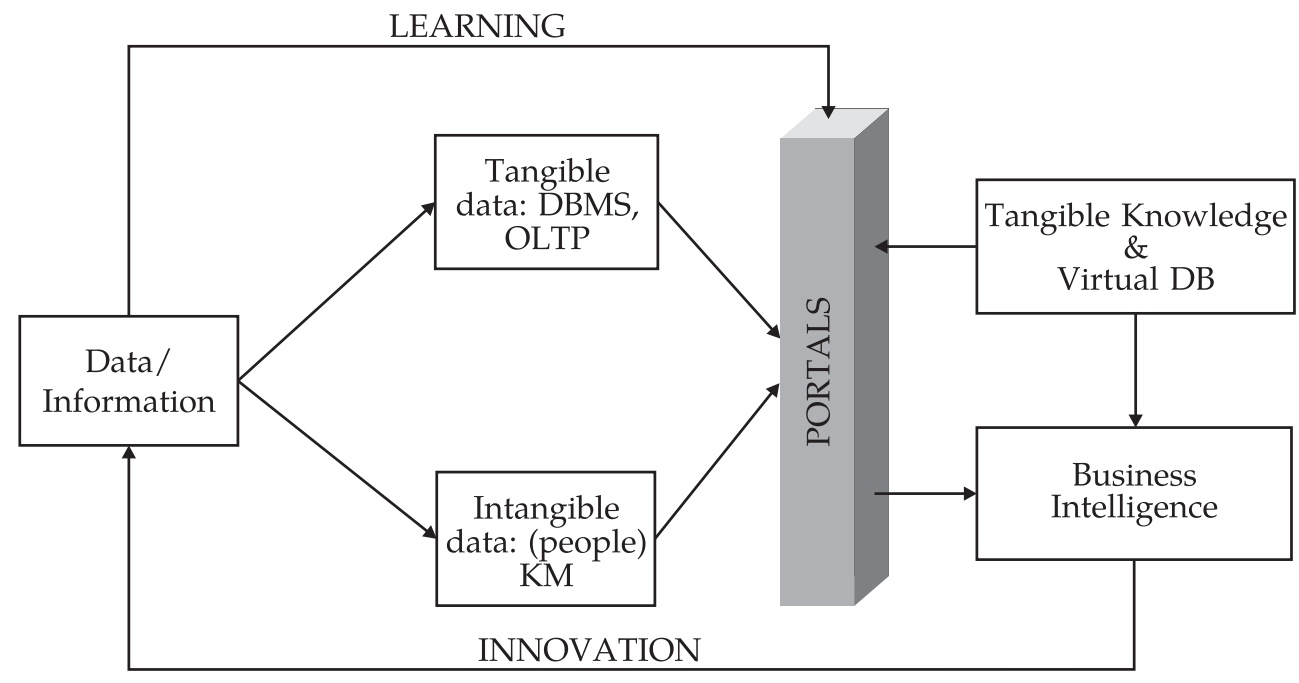

Fig. 3. KM - BI Model ( Campbell (2005)) 
Knowledge is information in action. It includes what people know about any process or approach. The conceptual KM-BI model of Fig. 3 suggests that with good information, people can make better decisions and take intelligent action, which leads to business intelligence at the organisational level. This model relates well with the framework for knowledge enablement in Fig. 2. KM is seen as a systematic process - as conceptualised from the KM-BI model, in this chapter, to:

1. Identify important knowledge: The KM-BI model acts as a framework for facilitating knowledge creation and transfer. The model assumes that the organisation's internal structural and cultural dimensions in which knowledge work processes must take place are already enabled.

2. Create a space and system for people to share what they know and create new knowledge: The environment in which knowledge work processes are realized "comprise social interaction and communication processes on an individual or group level. These processes may be categorized according to the transformation that knowledge undergoes as a result of the activity" (Schutte \& Preez (2008)). These being :

(a) Socialization - comprises the exchange of tacit knowledge between individuals in order to convey personal knowledge and experience.;

(b) Externalization - involves the conversion of implicit into explicit knowledge, and the exchange of knowledge between individuals and a group;

(c) Systematization - transforms explicit knowledge into more complex and more systematized explicit knowledge, and

(d) Internalization - is the conversion of organisation-wide, explicit knowledge into the implicit knowledge of the individual. These four knowledge work processes combine to form a spiral representing all the knowledge creation and transfer activities within the network.

3. Capture, collect and manage best practices and useful information in a form that other people can use in the future: This component of the model is the business intelligence which results from the resulting organisational learning, and the empowerment thereof. The KM-BI model (Campbell (2005)), and the knowledge network architecture (Seufert et al. (1999)) consist of tools that are used to facilitate social relationships, and include organisational, as well as information and communication protocols aimed at enabling or improving knowledge work processes. Gous \& Schutte (2009) suggest that a tool classification framework may be employed to divide the combination of organisational information system tools into four main categories: communication and coordination tools, organisation and management tools, intelligent tools and integration and database tools. This is with a view to ensure maximum impact on the knowledge network, these tools are used in combination to form "solution frameworks" (Seufert et al. (1999)) instead of operating as modular tools.

4. Transfer information, knowledge and best practices to others who can use it (von Krogh et al. (2000)).: Fig.1. sets out the modes of knowledge common in the knowledge spiral (Campbell (2009)), which, with the use of an Asynchronous Groupware (AG) infrastructure will facilitate this systematic process. The work of (Gous \& Schutte (2009)), concurs with the previous views of Campbell (2005), that "the creation of a knowledge portal to provide access to the knowledge network may be realized with modern web-based technologies. This provides a single point of access to the knowledge objects and all underlying systems. Such a knowledge portal should be configurable and adaptable to the needs of knowledge networks as well as the needs of their members" (Campbell (2009)). 


\subsection{Organisational learning}

Knowledge transfer is not a one directional movement of knowledge. Effective knowledge transfer is more than the movement of knowledge from one location to another. It is proposed that organisations can gain significant learning benefits through transferring knowledge between units and people. Competence tends to improve with those who transfer and share knowledge, because knowledge does not leave the owner when it has been transferred. As a result, the value of knowledge grows each time a transfer takes place. And, the key to knowledge transfer strategies should be based on the internal and the external structure of the organisation. As such, there are three main approaches to knowledge transfer, in terms of technology and organisational culture. The first approach, emphasizes the importance of the technological means and tools for effective knowledge transfer. The second, focuses more on the social interactions and underlying importance of cultural aspects. The third approach, is a comprehensive one, that aims to combine the technological perimeter with the socio-cultural perimeter of KM.

The challenge here is that managers either need to ensure the creation of unique knowledge that can be unleash in value-creating activity, or establish better use of public knowledge that is generally available to the organisation and its competitors (von Krogh et al. (2000)). The chapter reports this as organisational learning, in the KM-BI model (Campbell (2009) as illustrated in Fig. 3.

\subsection{Structural capital}

Knowledge is meaningful when it is codified, classified, given a shape, put in a useful format and stored. Only then can it be used by the right person, at the right time, in the right way. Storage and codification of knowledge is not only important for the effective use of knowledge, but also for re-using knowledge when it is needed; so the knowledge in question belongs to the organisation rather than the knower (Campbell (2005)). In this chapter, KM is viewed as a process. It is the process through which organisations create and use their institutional or collective knowledge. It has three sub-processes:

1. Organisational learning - the process through which the organisation acquires information and/or knowledge;

2. Knowledge production - the process that transforms and integrates raw information into knowledge which in turn creates BI, and is useful to solve business problems, and

3. Knowledge distribution - the process that allows members of the organisation to access and use the collective knowledge - corporate memory of the organisation.

The question one may ask is, how does this inform the concept of a knowledge system? In the context of the present chapter, a 'knowledge system', means the web of processes, behaviour and tools which enables the organisation to develop and apply knowledge to its business processes. It includes the infrastructure for implementing the KM process. There are usually two components here (Campbell (2005)):

Firstly, there is a robust IT infrastructure, including the organisation's database, computer networks, and software applicationns. This chapter is not advocating the need for just a good or popular relational database, or a sophisticated groupware, or email system - the Asynchronous Groupware component of the knowledge system [cf. Figure 3], it subsumes that there must be an organisational infrastructure, which supports innovation. This prescript resonates with the views of du Plessis (2007), who defines innovation, 
... as the creation of new knowledge and ideas to facilitate new business outcomes, aimed at improving internal business processes and structures and to create market driven products and services. Innovation encompasses both radical and incremental innovation.

This includes the soft characteristics of the system. There are incentives schemes, organisational culture, critical people and teams which are involved in the KM sub-processes. This also accounts for, most importantly, the internal rules that govern these sub-processes. This is the structural (knowledge) capital component of the knowledge system [cf. Figure 4]. In the structural capital framework, one should think of data as information devoid of context. Information is data in context, while knowledge is information with causal links. So within the logic of the knowledge system, the more structure that is added to a pool of information, the easier it will be for one to achieve the benefits of a knowledge system [cf. KM-BI model]. In this regard, the definition of a meaningful KM initiative should be aligned to the enterprise strategy. This would, therefore, mean the development of formal KM strategies, from which realistic and concrete goals can be derived. These strategies should be closely aligned with the three drivers of the application of knowledge in innovation advocated by Marina du Plessis (du Plessis (2007)):

The first basic driver for knowledge management's role in innovation in today's business environment is to create, build and maintain competitive advantage through utilization of knowledge and through collaboration practices. Cavusgil et al. (2003) indicate that building and sustaining an innovation program has, however, become increasingly complex due to changing customer needs, extensive competitive pressure and rapid technological change. organisations find it increasingly difficult to internalize innovations. Some large organisations such as Xerox and Hitachi have therefore started working collaboratively across organisational boundaries to ensure sustained innovation and competitive advantage (Cavusgil et al. (2003)). Knowledge management can facilitate such collaboration. Close collaborative relationships can provide access to the processes other organisations use that could be applied in different contexts. Acquiring knowledge and skills through collaboration is considered to be an effective and efficient way of successful innovation.

The second driver of the role of knowledge management in innovation is that knowledge is a resource used to reduce complexity in the innovation process, and managing knowledge as resource will consequently be of significant importance. Innovation is extremely dependent on the availability of knowledge and therefore the complexity created by the explosion of richness and reach of knowledge has to be recognized and managed [Adams \& Lamont (2003); Cardinal et al. (2003); Darroch \& McNaughton (2002); Pyka (2002); ?]. According to ? the upsurge in the amount of knowledge that is readily available to organisations seems to add increased complexity to the design and management of new product development, but this complexity can be addressed by knowledge management and knowledge-intensive units in the organisation that are strategic in nature. Cavusgil et al. (2003) agree that knowledge management is a mechanism through which innovation complexity can be addressed. It assists in managing new knowledge created through the innovation process, but also in managing existing knowledge as a resource used as input to the innovation process. Cavusgil et al. (2003) are of the opinion that firms that create and use knowledge rapidly and effectively are able to innovate faster and more successfully than those that do not. According to Pyka (2002), creation of innovation networks are driven by synergistic creation and management of knowledge.

The third driver of applying knowledge management to the benefit of the innovation process is the integration of knowledge both internal and external to the organisation, thus making 
it more available and accessible. Knowledge integration implies that timely insights can be made available to be drawn at the appropriate juncture for sense making, i.e. knowledge can be exchanged, shared, evolved, refined and made available at the point of need. Knowledge integration via knowledge management platforms, tools and processes must therefore facilitate reflection and dialogue to allow personal and organisational learning and innovation. This requires linkability, adaptability and dynamic representation of business information and knowledge. Without effective information and knowledge management that drives knowledge integration, which in turn underpins innovation, organisations could be underutilizing knowledge as an innovation resource [Baddi \& Sharif (2003); Chen et al. (2004)]. The above three drivers resonate with the prescript for organisational learning, knowledge production, and knowledge distribution, which define the concept of a knowledge system, and a basic requirement for the enablement of structural capital. Given the foregoing, we can now explore the component of human capital.

\subsection{Human knowledge}

The focus of this component, human knowledge, of the knowledge system is on knowledge creation and knowledge dissemination. This is not to suggest, in any way, that knowledge utilisation is not just as important. Rather, the elements comprising knowledge utilisation are subsumed here. The component of human knowledge involves the process of knowledge acquisition, which looks at the integration of external knowledge in the enterprise. This integration is by means of recruiting knowledge workers, specialists with particular value adding expertise, who usually bring relevant experience to the enterprise to assist it to meet its strategic objectives. The period over which this method of knowledge acquisition is used can be for different life cycles, ranging from permanent to project specific duration.

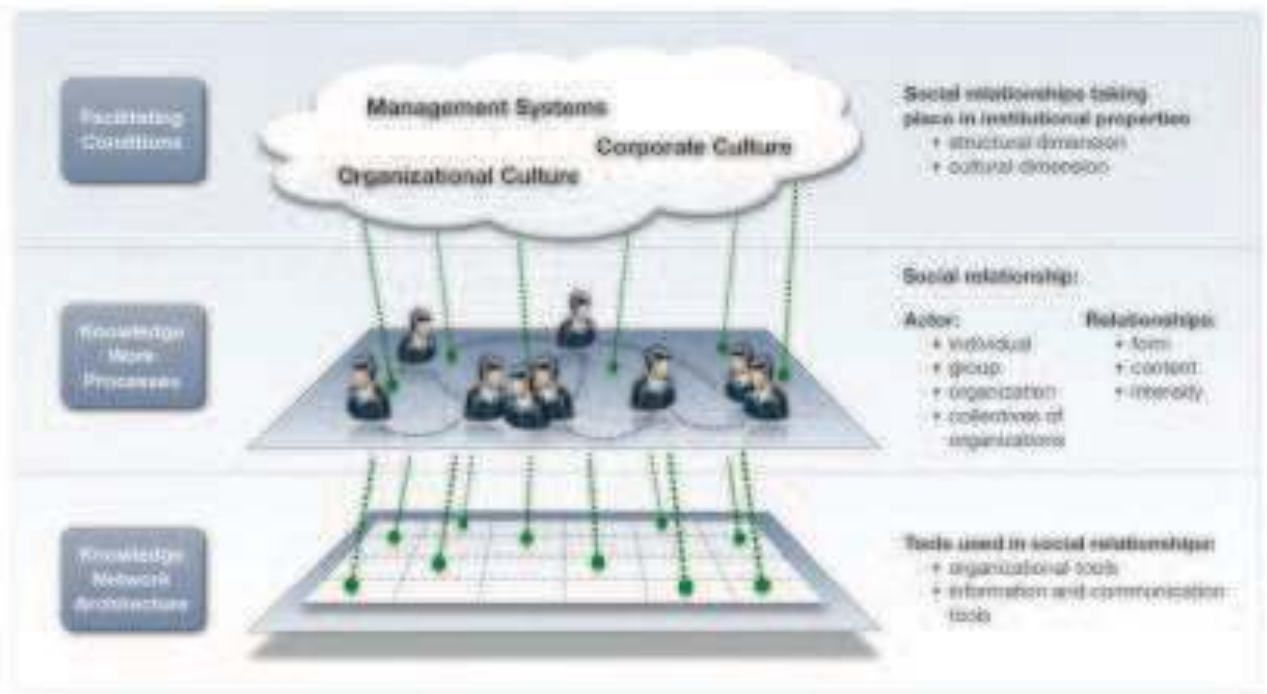

Fig. 4. A framework for knowledge networks (Gous \& Schutte (2009))

Allied to this, though, is the active process of knowledge development, which involves not only the functions of knowledge production in the formal sense of the concept of the development of a process, or a product, or service for consumption in terms of the commercial 
milieu, but it also includes the performance metrics of an organisation. This is not to say that, that the development of knowledge and knowledge creation initiatives, in the physical sense, in the organisation's $\mathrm{R}$ and D department is not important. One is arguing that the processes used in the investigation and communication of that knowledge is more important than in the context of product creation and production. The generation of new ideas, abilities and products (of course) must be considered in addition to the other innovative processes of the enterprise. A central role of knowledge development is the promotion of creativity and communication among employees through the integration of enabling knowledge sharing strategies and an appropriate collaboration framework.

The presence of an appropriate organisational culture is a prerequisite for successful knowledge development. The analogy is like the role played by technological devices and tools within the spectra from telephones and whiteboards, to videoconferences and groupware, but more specifically asynchronous groupware (AG). Nonaka \& Takeuchi (1995) argue that knowledge development is based on the interaction of implicit and explicit knowledge as the basis for the generation of new knowledge. Also, from the literature, Nonaka \& Nishiguchi (2001) specifies a model for organisational knowledge development, which he calls the spiral of knowledge. This model is replicated in Fig. 1.

\section{Research goal}

The research goal of this chapter is to provide some insights from the literature surveyed and suggest how the innovation processes and network dynamics in terms of the need for intra-organisational collaboration, and the possible types of strategies organisations must devise through external networks. So they would be able to access the requisite knowledge for competitive advantage and business intelligence. This is with a view to lead to a robust discussion on how innovation may be supported by an integrated knowledge network, and whether the current ICT architecture available to organisations can offer the necessary functionality.

The research problem is conceptualized on the premise that: "innovation within a globalized economy requires that a wide range of role-players along a knowledge management network of collaboration by transferring and creating knowledge." A mechanism that offers this functionality is required.

This chapter, therefore, hypothesized that "innovation may be supported by an integrated knowledge network, that is an ICT architecture that offers the following functionality, such as:

- support for all the necessary knowledge work processes needed for knowledge creation and transfer within an Integrated Knowledge Network, and

- support for the full innovation life cycle of projects that develop within the integrated knowledge network." Gous \& Schutte (2009)

\subsection{Value proposition in the innovation-oriented process}

Such a system would be circumscribed by an articulated value proposition. The value proposition of the role of knowledge management in an innovation-oriented intellectual capital milieu plays an invaluable role in fostering business intelligence, and intellectual capital, organisational knowledge, and structural knowledge, towards enabling an organisation's competitive advantage. Marina du Plessis [du Plessis (2007)] defines this value proposition as follows: 
1. Knowledge management assists in creating tools, platforms and processes for tacit knowledge creation, sharing and leverage in the organisation, which plays an important role in the innovation process. Knowledge management provides a focus in the organisation on the value of tacit knowledge and assists in creating the environment for tacit knowledge creation, sharing and leverage to take place. An example would be through creation of communities of practice around areas of innovation that requires attention in the organisation. Knowledge could also provide other platforms and processes for tacit knowledge sharing, such as breakfast briefings. Knowledge management can also facilitate tacit knowledge transfer across organisational and inter-organisational boundaries through ensuring that experts with relevant expert knowledge have opportunities to share their tacit knowledge through collaboration. Knowledge management can also assist in identifying stocks of available tacit knowledge.

2. Knowledge management assists in converting tacit knowledge to explicit knowledge. It can provide both the platforms as well as the processes to ensure that tacit knowledge becomes explicit. Examples of codification platforms include discussion databases or online collaborative communities of practice. An example of a process to codify tacit knowledge to explicit knowledge is the capturing of tacit knowledge at tacit knowledge sharing events such as breakfast briefings into an electronic form where the knowledge can be organized and retrieved for later use. This adds a lot of value to the organisation as it is known what knowledge is available, and it is retrievable for future re-use.

3. Knowledge management facilitates collaboration in the innovation process. Knowledge management allows collaboration across functional boundaries within organisations, but also across organisational boundaries through online collaboration forums as well as organisational tools and platforms such as intranets and extranets. These collaboration forums are extremely valuable as they ensure the codification of knowledge utilized as input to the innovation process, but also generated as output of the innovation process. It provides accessibility to the knowledge and provides identification of collaborators in the knowledge sharing and innovation process, thus building up a reference of expertise and where it resides in the organisation. It also ensures that knowledge external to the organisation relevant to the organisation's innovation processes is available and accessible.

4. Knowledge management ensures the availability and accessibility of both tacit and explicit knowledge used in the innovation process using knowledge organisation and retrieval skills and tools, such as taxonomies. It allows the organisation and retrieval knowledge in a structured way according to the unique structures and value chain of the organisation. It also provides search facilities and tools (e.g. Autonomy, Convera, and others) to enable staff to search for knowledge required in the innovation process. It provides a unique corporate structure to the corporate knowledge base. It can also make tacit knowledge more accessible through directories that identify individuals' areas of expertise in the organisation.

5. Knowledge management ensures the flow of knowledge used in the innovation process. Through the provision of collaboration forums and knowledge management processes, knowledge required for the innovation process can flow easily across functional boundaries as well as across organisational boundaries to facilitate internal and external collaboration. Creation of a knowledge sharing culture, which is an essential part of any knowledge management program, also stimulates knowledge flow, which is beneficial for innovation. 
6. Knowledge management provides platforms, tools and processes to ensure integration of an organisation's knowledge base. Through knowledge management structures such as taxonomies, knowledge management can ensure the integration of the corporate knowledge base. This enables staff members to have an integrated view of what knowledge is available, where it can be accessed, and also what the gaps in the knowledge base are. This is extremely important in the innovation process to ensure that knowledge as resource is utilized to its maximum benefit and to ensure that knowledge is not recreated in the innovation process.

7. Knowledge management assists in identifying gaps in the knowledge base and provides processes to fill the gaps in order to aid innovation. Through the structured provision of access to knowledge, knowledge management provides an overview of what is available in the organisation. This allows the organisation to understand in which areas knowledge is lacking and to systematically build the knowledge base in these areas. The organisation may do this through the innovation program itself if the gaps are in strategic areas, but it may also do it through knowledge management processes or operational business processes.

8. Knowledge management assists in building competencies required in the innovation process. Through knowledge accessibility and knowledge flow, staff members are able to increase their skills levels and knowledge both formally and informally. An increase in skills can improve the quality of innovation. The flow of knowledge across functional boundaries ensures that a wider base of knowledge is available to employees than only the knowledge they use in their day-to-day activities. Employees therefore have a wider frame of reference of the context in which they work and will therefore be able to innovate more efficiently. Knowledge management also provides a culture of knowledge sharing and accessibility of knowledge, creating an environment conducive to skills and competency building, which aids innovation.

9. Knowledge management provides organisational context to the body of knowledge in the organisation. Every organisation's corporate memory is unique. The structures provided to organize and retrieve knowledge from the corporate knowledge base will therefore be providing a unique context to each particular organisational knowledge base. Provision of organisational context is critical in the innovation process, as innovation in the organisation also takes place within a very specific business context. Knowledge management assists in identifying and understanding this organisational context.

10. Knowledge management assists in steady growth of the knowledge base through gathering and capturing of explicit and tacit knowledge. It also assists specifically in addressing gaps in the knowledge base through specific acquisition of knowledge in those areas where gaps exist, or through knowledge creation and innovation itself. This in turn feeds the innovation process through creation of a much broader knowledge base that is available as resource for the innovation process. The tacit knowledge base also grows through building of skills due to the availability of knowledge.

11. Knowledge management provides a knowledge-driven culture within which innovations can be incubated. Knowledge sharing is enhanced by a culture where the role of knowledge, knowledge management, innovation and creative thinking is encouraged. Most knowledge management programs have a strong knowledge culture element through which an organisational culture of knowledge generation and sharing is emphasized. This benefits innovation programs as it provides knowledge as resource, 
but it also provides a culture within which innovation, creativity and learning through mistakes are encouraged and valued.

The goal of this chapter is therefore to suggest the design of an information system that facilitates an integrated knowledge network, or a knowledge management - business intelligence (KM-BI) portal [cf. Fig. 3.], while providing support for the full life cycle of innovation projects that develop within this network, following from the work of Gous \& Schutte (2009).

\section{Drupal}

During the implementation phase of the computerised personnel management system (CPMS) project at Directorate, we found that the available innovation management software did not provide much ICT solutions with regard to an integrated knowledge network. The literature also had only few successful projects which had integrated knowledge networks as a part of their web technologies. The few available web technologies, we found, offer remote connectivity, content management, media-rich environments, community building and social networking.

All these technologies had relevance to the nature and scope of the requirements of the Information Systems project definition of Directorate in terms of its integrated knowledge management work processes and value chain. The literature supports the view that an organisation's integrated knowledge network is "... a cradle for Innovation in a modern environment, and the exact features many of these technologies boast" [Gous \& Schutte (2009)]. We found that the latest web technologies which were noteworthy, are mainly open-source content management system, among these are WordPress, Joomla, and Drupal [Buytaert (n.d.)], which support content management. We also found that the standard release of Drupal, known as "Drupal core", contains basic features common to most Content Management Systems (CMS). These include the ability to register and maintain individual user accounts, administration menus, RSS-feeds, customizable layout, flexible account privileges, logging, a blogging system, an Internet forum, and options to create an interactive community website [Gous \& Schutte (2009)] We concur with Gous \& Schutte (2009) that "Drupal was also designed to allow new features and custom behaviour to be added by third parties. For this reason, Drupal is sometimes described as a "Content Management Framework." Although Drupal offers a sophisticated programming interface for developers, no programming skills are required for basic web site installation and administration."

At Directorate, the system was designed to support the integrated work carried out by the personnel administration, recruitment, and placement divisions. Internal users of the system were intended to be able to store up-to-date information about public officers in their ministries, and keep track of policy development provided by Directorate through the online Policy Database. In order to meet this requirement, some of the positive and negative considerations of Drupal are set out next

1. Positive aspects of Drupal:

- Flexible framework for the development of web-based applications

- Vibrant developer community on the Drupal site

- New content types are easily created and may be extended with the Content Construction Kit module

- Fully customizable user permissions

- The Organic Groups module provides unrivalled community building functions 
- Dynamic approach to content handling

- The Taxonomy module is unparalleled in the CMS landscape and allows for predefined content classification, as well as free tagging

- The Views module allows for custom views of any content within the content pool

2. Negative aspects of Drupal:

- Limited availability of themes

- Steeper learning curve than many other CMS packages

Despite Drupal's steep learning curve, it creates a framework that offers extendibility far beyond most other CMS packages and is supported by a vibrant and helpful community of knowledgeable developers and users. Drupal includes a number of features and extensions (Taxonomy, Organic Groups, Content Construction Kit, Views) that allow developers to create highly customized web-based community platforms. Drupal was therefore chosen as the basis of the proposed Information System.

\section{Directorate}

This section describes an iteration of the action research (AR) cycle conducted at Directorate ${ }^{3}$, one of the human resources department of the public service in Botswana. Directorate had a staff complement of 435 , and 8 functional divisions at the start of the iteration. These divisions are spread over four offices throughout the country. Communication between these offices is via traditional means: post, telephone, facsimile and also the application of groupware technology, namely email (Lotus Notes ${ }^{4}$, and a corporate intranet. The Government Data Network (GDN) supports the groupware application. All four offices were connected via the GDN. All senior officers had computers in their individual offices, which were networked in a campus network, and connected to the GDN. They all had access to the Lotus Notes mail server, and Domino Docs ${ }^{5}$ database.

Each officer had an email address assigned to him/her, and was able to communicate with each other without any difficulty.

\subsection{System requirements and design}

A multi-layer approach was used to ensure that all the requirements of the aforementioned solution are considered. The information system architecture requirements of an integrated knowledge network (i.e. the knowledge network architecture and the knowledge work processes) of CPMS at Directorate were considered first, after which a similar set of requirements was derived for the innovation life cycle [cf. Fig. 5].

Combining these requirement sets provided an information system architecture specification that was used to develop the Information System that serves as a proposed solution for the problem at Directorate. After about two years of development, the system finally achieved an acceptable level of efficiency. It was decided by management to introduce new technologies which would provide greater understanding and knowledge on the core processes. An external consultant was engaged to define these processes. Interviews were conducted to this end. The approach followed is discussed next.

Before decentralisation, Directorate was nearly 100\% responsible for keeping the CPMS system up-to-date. Since decentralisation the following is true:

\footnotetext{
${ }^{3}$ The Directorate is the short name for the Directorate of Public Service Management.(DPSM)

${ }^{4}$ Lotus Notes Corporation

${ }^{5}$ Data Base Management System of Lotus Corporation
} 


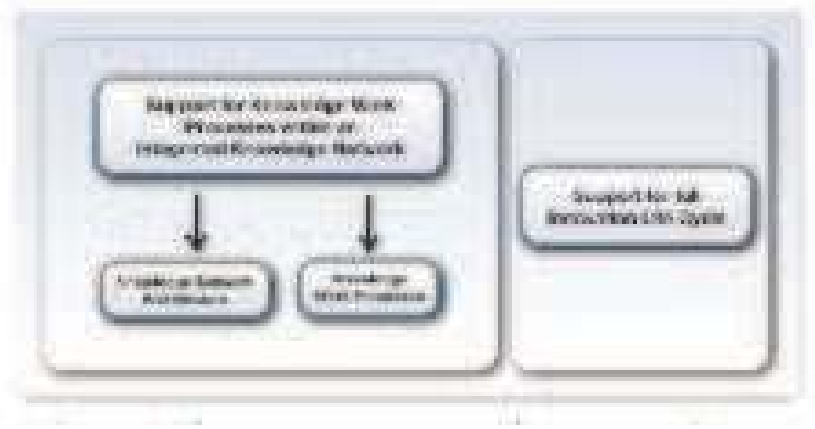

Fig. 5. A multilayer approach for the systems requirement (Gous \& Schutte (2009))

1. The Recruitment, Personnel Administration, and Training Divisions, which were the major players using the system, have now become occasional users;

2. The Manpower Planning Division owns the responsibility to create and change positions in the Establishment Register; and

3. The Industrial Class Division, which was already decentralized only, needs the system for enquiries. For the ministries, however, there was a big increase in usage and responsibility to keep the computer system up-to-date. The ministries now have complete ownership of the system except for the creation and changing of positions which still belongs to the Manpower Planning Division. The effect that decentralisation has had on the CPMS is three-fold:

- where the system had one owner, responsible for the usage and ensuring that the information in the system was being kept up-to-date, there were now 18 ministries and independent departments that were responsible;

- no roles and responsibilities were formally clarified, which created confusion. This confusion forced the project to stop its planned work on the HRM Workflow Management System (WMS), as a WMS needs a very disciplined and focused environment, with every-one concerned knowing exactly what were their roles and areas of responsibility; and

- system training was not only required at the Directorate level anymore, but at also at ministries' as well. This necessitated the change in scope and focus of the implementation of the CPMS project. For the project team to successfully implement the system at the ministries' level, it was imperative to ensure that the HR processes used by them were integrated with the CPMS. In the process of identifying this requirement, two other issues came to light, namely:

- whether the ministries had any formalised processes to build on, and

- ownership of the HR processes (personnel actions). The need that was jointly identified for the project, Directorate and the ministries, was a requirement for a process manual with each HR process defined where the following is clarified:

* what must be done, and

* who is responsible.

This process manual could then be used to compile the operational manual by adding 'how' each step must be done. The key benefit from this manual is that it would enable Directorate, and the identified trainers to teach and train all the ministries in what must be done and 
how it should be done, using the computer system, in order to ensure that the system is kept up-to-date. For the CPMS to succeed in the Public Service, it requires that each ministry must keep their information in the system up-to-date. If the ministries fail to comply, the money already spent on the implementation phase of the project would go to waste, and the data would become outdated and useless. The only way, it was felt, to ensure that the system is updated, and is available, is by ensuring that no personnel action can be executed without the use of the computer system in the process. For example, public officer should not be able to:

- hire without using the CPMS;

- promote someone without using the CPMS, and

- send someone for training without using the CPMS.

Several unstructured interviews conducted at this stage revealed symptoms of an organisation in which the process of learning involved in adapting to a fast changing business environment was the sole responsibility of its top management. Permanent Secretaries of ministries were unhappy with the current system. Government expressed dissatisfaction with the lack of service delivery of the system. A major reengineering of the system was required. Employees were unmotivated, reporting as the most important reason for their lack of motivation was the excessive centralisation of decisions by the divisional managers. Employees showed no interest in either improving business processes, or learning new methods and techniques. It was noted by one manager that: "What keeps [the employees] working are their monthly pay cheques and the prospects of overseas per diems, travel, seminars and training at international colleges and universities."

The inability to motivate officers at the Directorate called for changes in the management approach. Some techniques for enhancing the level of employee participation in decisions were tested; among these techniques were brainstorming sessions, suggestion boxes, and campaigns for new ideas to solve specific problems.

None of these techniques generated the expected gains, due to two reasons. Firstly, they were strictly based on the assumption that front-line workers should have an active role in management and solution of problems, which is one of the several facets of process improvement. For example, employees were called to participate in routine strategic decisions [Campbell (2005)]. However, this proved to be a counter-productive strategy, supporting the assumption that group decisions may not be better than individual decisions. Strategic decisions to form new partnerships or sign a large government contract, for example, were found to be better made only by managers as usual.

Directorate experience suggested that sharing the responsibility of taking some types of decisions with large groups of employees not directly involved with decision making on a daily basis simply delayed what could not be delayed, undermining both the employee' and management's confidence in participatory management principles. There were a number of problems experienced during this phase. These were exacerbated due to a lack of ownership on the part of management. They include such issues as budgeting and funding concerns, the rigid structure of the ministry management, massive staff turnover, poor project ownership, and the absence of a proper system protocol, and data availability regime. Secondly, the analysis and redesign of the human resource processes received a low priority status in the public sector's reform initiatives, and national development plans.

For example, by the time this research iteration had begun, the whole set of interrelated activities involved in reviewing the pay structures and performance incentives, from consultants engaged to study the relationships between private sector and public sector remuneration, and the Presidential Commission on salary structures coupled with the 
implementation difficulties of the performance management system (PMS), had not been addressed by government in at least three years. The emphasis was on having employees participate in management decisions, rather than in the analysis of how activities were executed and improvements could be attained. Moreover, new ideas for improvement coming from employees covered an overly broad range of subjects, from new designs for promotional material to better wages, leading to a vast amount of contributions coming from staff that had little knowledge about the work of the areas likely to be affected by the ideas. This, and the repetition of ideas, progressively undermined the interest of managers, and consequently employees' motivation to generate new improvement ideas.

The researcher will now discuss the experiences observed in implementing a KM system.

\subsection{Diagnosing}

Directorate decentralised its portfolio responsibilities to the human resources (HR) divisions of client ministries in 1998. The new role of Directorate was now one of policy formulation, etc. Directorate is one of the leaders in facilitating the nation's Vision 2016, and it has a number of reform initiatives currently being implemented. However as the public sector has grown, problems have arisen in the effective managementof the human resources management (HRM). Directorate gets its authority from the Public Service Act, (1998). Several unstructured interviews conducted at this stage revealed symptoms of the computerised personnel management system (CPMS), and a number of suggestions were provided as to how Directorate may alleviate them. The system had a number of problems at the onset. This was because the model of Directorate and the clients it serves were not properly specified. The Management of Directorate relied on the services of the commercial brokers to advise them on the choice of the HRM solution to purchase. All this was done before a proper system operations and user requirements documents was completed and proved by the senior management of Directorate. Additionally, systems personnel and developers for both the administrative and technical areas required for staffing the new infrastructure were not implemented. There was a major concern about the budgeting requirements for the different phases of the project.

The system was designed to support the integrated work carried out by the personnel administration and recruitment and placement divisions. Internal users of the system were intended to be able to store up-to-date information about public officers in ministries and keep track of policy development provided by Directorate through the online Policy Database. These processes are listed in paragraph 5.3 [cf. List of core processes].

\subsection{List of core processes}

After about two years of development, the system finally achieved an acceptable level of efficiency. It was decided by management to introduce new technologies which would provide greater understanding and knowledge on the core processes. An external consultant, was engaged to define these processes. Interviews were conducted to this end. The approach followed is discussed next. Before decentralisation, Directorate was nearly $100 \%$ responsible for keeping the CPMS system up-to-date. Since decentralisation the following is true:

- The Recruitment, Personnel Administration, and Training Divisions, which were the major players using the system, have now become occasional users;

- The Manpower Planning Division owns the responsibility to create and change positions in the Establishment Register; and 
- The Industrial Class Division, which is already decentralized only needs the system for enquiries.

For the ministries, however, there was a big increase in usage and responsibility to keep the computer system up-to-date. The ministries now have complete ownership of the system except for the creation and changing of positions which still belongs to the Manpower Planning Division. The effect that decentralisation has had on the CPMS is three-fold:

- where the system had one owner responsible for the usage and ensuring that the information in the system was being kept up-to-date, there are now 18 ministries and independent departments that are responsible;

- no roles and responsibilities were formally clarified, which created confusion. This confusion forced the project to stop its planned work on the HRM Workflow Management System (WMS), as a WMS needs a very disciplined and focused environment, with everyone concerned knowing exactly what are their roles and areas of responsibility; and

- system training was not only required at the Directorate level anymore, but at ministries as well. This necessitated the change in scope and focus of the implementation of the CPMS project.

To enable the project to successfully implement the system at the ministries, it was imperative to ensure that the HR processes used by the ministries are integrated with the CPMS. In identifying this requirement, two other issues came to light, namely:

- whether the ministries had any formalised processes to build on, and

- ownership of the HR processes (personnel actions). The need that was jointly identified for the project, Directorate and the ministries, was a requirement for a process manual with each HR process defined where the following is clarified:

- what must be done, and

- who is responsible.

This manual could then be used to compile the operational manual by adding 'how' each step must be done. The key benefit from this manual is that it would enable Directorate, and the identified trainers to teach and train all the ministries in what must be done and how it should be done, using the computer system, in order to ensure that the system is kept up-to-date. For the CPMS to succeed in the Government, it requires that each ministry must keep their information in the system up-to-date. If the ministries fail to comply, the amount already spent on the implementation phase of the project would go to waste, and the data would become outdated and useless. The only way, it was felt, to ensure that the system is updated, and is available, is by ensuring that no personnel action can be executed without the use of the computer system in the process. For example, and officer should not be able to:

- hire without using the CPMS;

- promote someone without using the CPMS, and

- send someone for training without using the CPMS.

The following is the models used in developing the processes in the process manual. The core processes included in the manual, which show officers the process to follow, in terms of the identified personnel actions are also set out. The process manual when completed is expected to be used in conjunction with the system's Procedure Manual, where the process shows an activity to be done by the CPMS. 


\subsection{The high-level enterprise model}

HRM in the Botswana Government can be illustrated as set out in the policy-making framework, on people management, of Figure ??. Furthermore, in theory, any successful organisation and department needs four different types of groups of processes to function effectively. These groups types are presented in Figure ?? [cf. Figure ?? Different groups of process in organisational management].

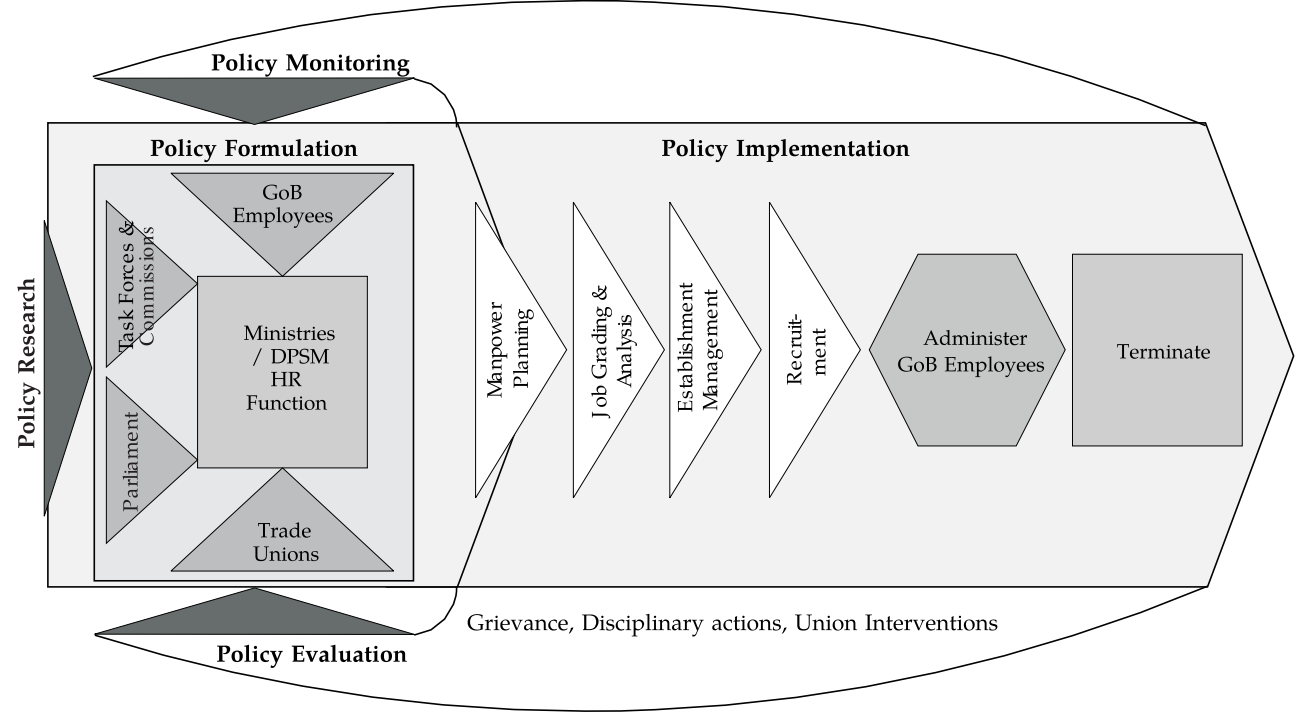

Fig. 6. HRM policy-making framework

Based on the researcher's knowledge of HRM, as well as the theory regarding processes and process groupings, the HR processes can now be broken down into these four groups. This is set out in Table 1 [cf. Table 1 List of processes]. Each process performed by the HRM function should be able to fit into one of these four groupings. If there are, for example, no processes in the Governing Processes group, it means that there is currently no control function and policymaking in terms of HRM. The study uses this information, to compile an enterprise model for the HRM function in the Botswana Government. An enterprise model is a holistic picture of the HRM function within the Botswana Government, which shows all the high level processes and the links between them.

The enterprise model has the same form as the physical building in which the ministries are situated:

- Roof: The customer interfacing processes (the part of one organisation that the customer can see);

- Walls: The enabling and governing processes (the barriers in between, in which one has to function);

- Floor: The processes, which assist one in delivering a first-class service,. For example, research and development, etc; and

- Living area: The main reason for having the house, that is, the value-adding processes of the HRM function. 


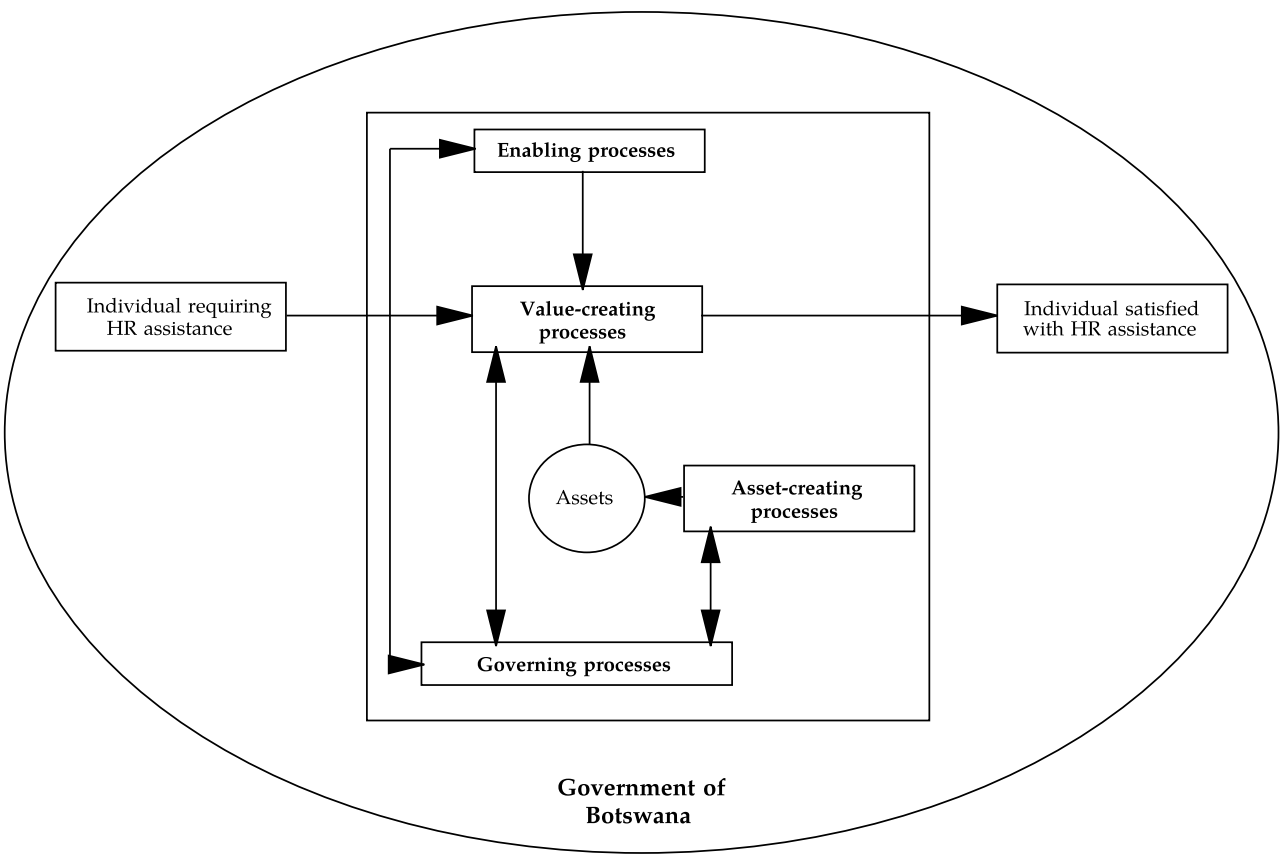

Fig. 7. Different groups of process in organisational management

\begin{tabular}{|c|c|c|c|}
\hline $\begin{array}{l}\text { Governing } \\
\text { processes }\end{array}$ & $\begin{array}{l}\text { Value-creating } \\
\text { processes }\end{array}$ & $\begin{array}{l}\text { Asset-creating } \\
\text { processes }\end{array}$ & \begin{tabular}{|l|} 
Enabling \\
processes
\end{tabular} \\
\hline $\begin{array}{l}\text { - Align with Vision } 2016 \\
\text { - Align with National } \\
\text { Development Plan } \\
\text { - Determine Budgets } \\
\text { - Formulate Policy } \\
\text { - Monitor Policy } \\
\text { - Evaluate Policy }\end{array}$ & $\begin{array}{l}\text { - Analyse jobs } \\
\text { - Plan manpower } \\
\text { - Recruit } \\
\text { - Administer } \\
\text { - Terminate }\end{array}$ & $\begin{array}{l}\text { - HR Research } \\
\text { - HR System } \\
\text { - Knowledge System }\end{array}$ & $\begin{array}{l}\text { - Financial management } \\
\text { - Records keeping } \\
\text { - Advertising } \\
\text { - Public Relations } \\
\text { - Employee Relations } \\
\text { (Law) } \\
\text { - Operations (Ministries } \\
\text { \& Parastatals) } \\
\text { - IT Operations }\end{array}$ \\
\hline
\end{tabular}

Table 1. List of processes 


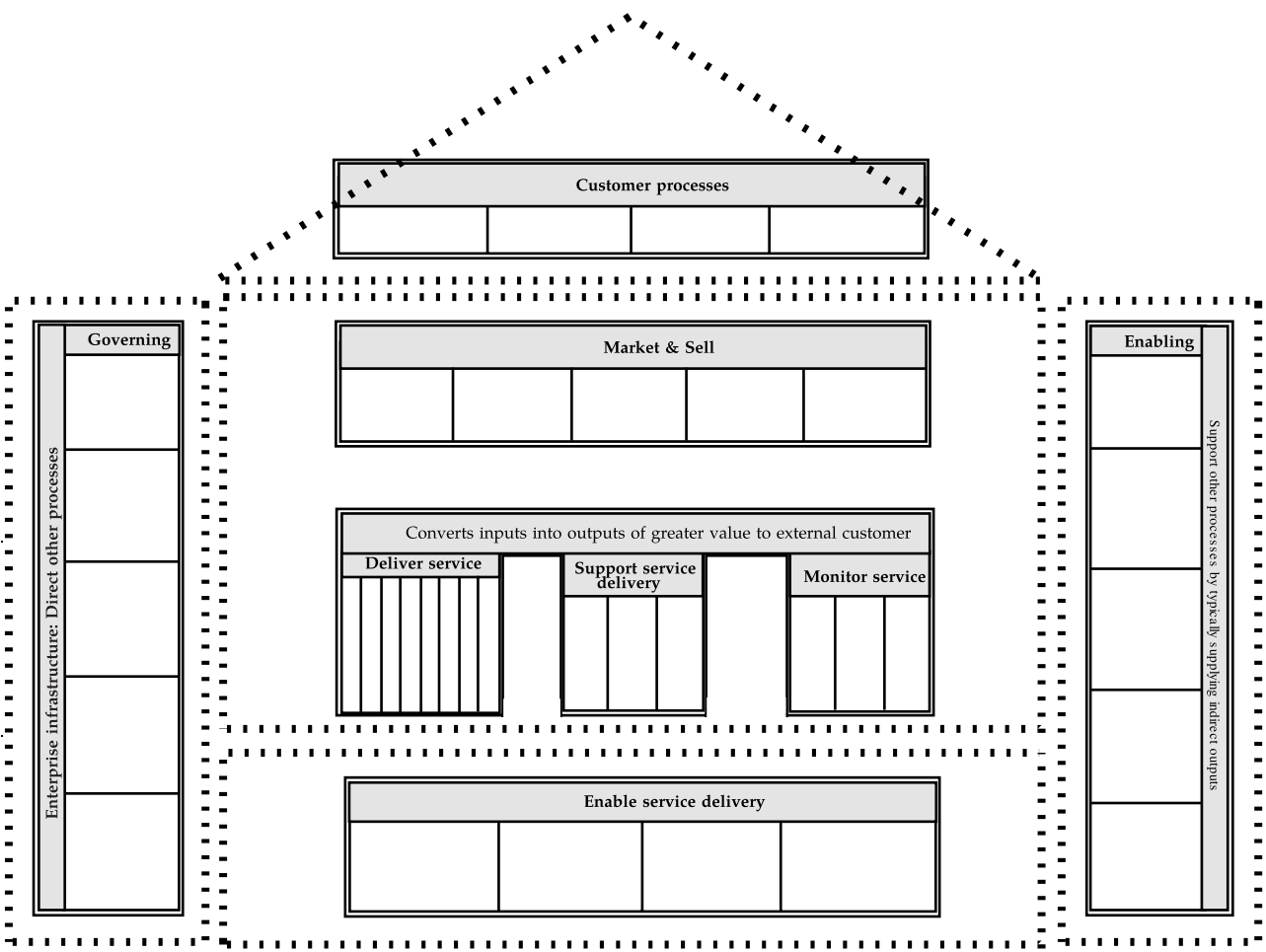

Fig. 8. Conceptual model of the HR function Source: Government of Botswana, 2000

There are a number of reasons, for having an enterprise model, in an organisation. The following reasons were used in Botswana, for building the enterprise model for this project:

- It's an articulation of the personnel action's strategic intent;

- It tells the story of how HR faces its "customers";

- It provides a non-traditional perspective that stimulates other non-traditional ideas;

- It provides a context for integration;

- It's irrelevant whether it is the "As is" or the "To be"

- It tells us what we do, not how we do it;

- It's a description of what the business is all about, and

- It's how we pick our targets for re-engineering.

Characteristics of a good enterprise model:

- Shows the interfaces with the customer processes;

- Contains a logical flow;

- Has only a few clear processes;

- Has clearly definable and measurable results;

- Is action oriented; 
- Not generic;

- Centres on value-adding processes;

- Describes everything that occurs in the organisation;

- Uses pictures, not words.

The High-level Enterprise Model, for the HRM function of the Government of Botswana, may then be modelled in the following process:

(i) Recruitment process;

(ii) Promotion process;

(iii) Upgrading process;

(iv) Transfer process v. Personnel Updates - Where the Employee requests an update (e.g. Personal Information);

(v) Personnel Updates - Where the Line Manager requests an update (e.g. Confirmation);

(vi) Termination - Retirement;

(vii) Termination - Resignation;

(viii) Termination - Dismissal;

(ix) Termination - Death;

(x) Termination - Probation;

(xi) Training - Planning;

(xii) Training - Budgeting;

(xiii) Training - Administration;

(xiv) Manpower Planning; and

(xv) Industrial Class.

Several unstructured interviews conducted at this stage revealed symptoms of an organisation in which the process of learning involved in adapting to a fast changing business environment was the sole responsibility of its top management. Permanent Secretaries of ministries were unhappy with the current system. Government expressed dissatisfaction with the lack of service delivery of the system. A major reengineering of the system was required. Employees were unmotivated, reporting as the most important reason for their lack of motivation was the excessive centralisation of decisions by the divisional managers. Employees showed no interest in either improving business processes, or learning new methods and techniques. It was noted by one manager that: "What keeps [the employees] working are their monthly pay cheques and the prospects of overseas per diems, travel, seminars and training at international colleges and universities". The inability to motivate officers at the Directorate called for changes in the management approach. Some techniques for enhancing the level of employee participation in decisions were tested; among these techniques were brainstorming sessions, suggestion boxes, and campaigns for new ideas to solve specific problems.

None of these techniques generated the expected gains, due to two reasons. Firstly, they were strictly based on the assumption that front-line workers should have an active role in management and solution of problems, which is one of the several facets of process improvement. For example, employees were called to participate in routine strategic decisions. However, this proved to be a counterproductive strategy, supporting the 


\begin{tabular}{|c|c|c|c|c|c|c|c|}
\hline \multicolumn{8}{|c|}{ Support other processes by typically supplying indirect outputs } \\
\hline 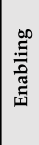 & 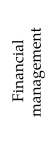 & 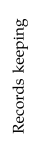 & 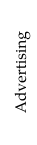 & 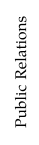 & 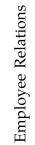 & 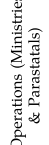 & 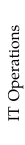 \\
\hline
\end{tabular}
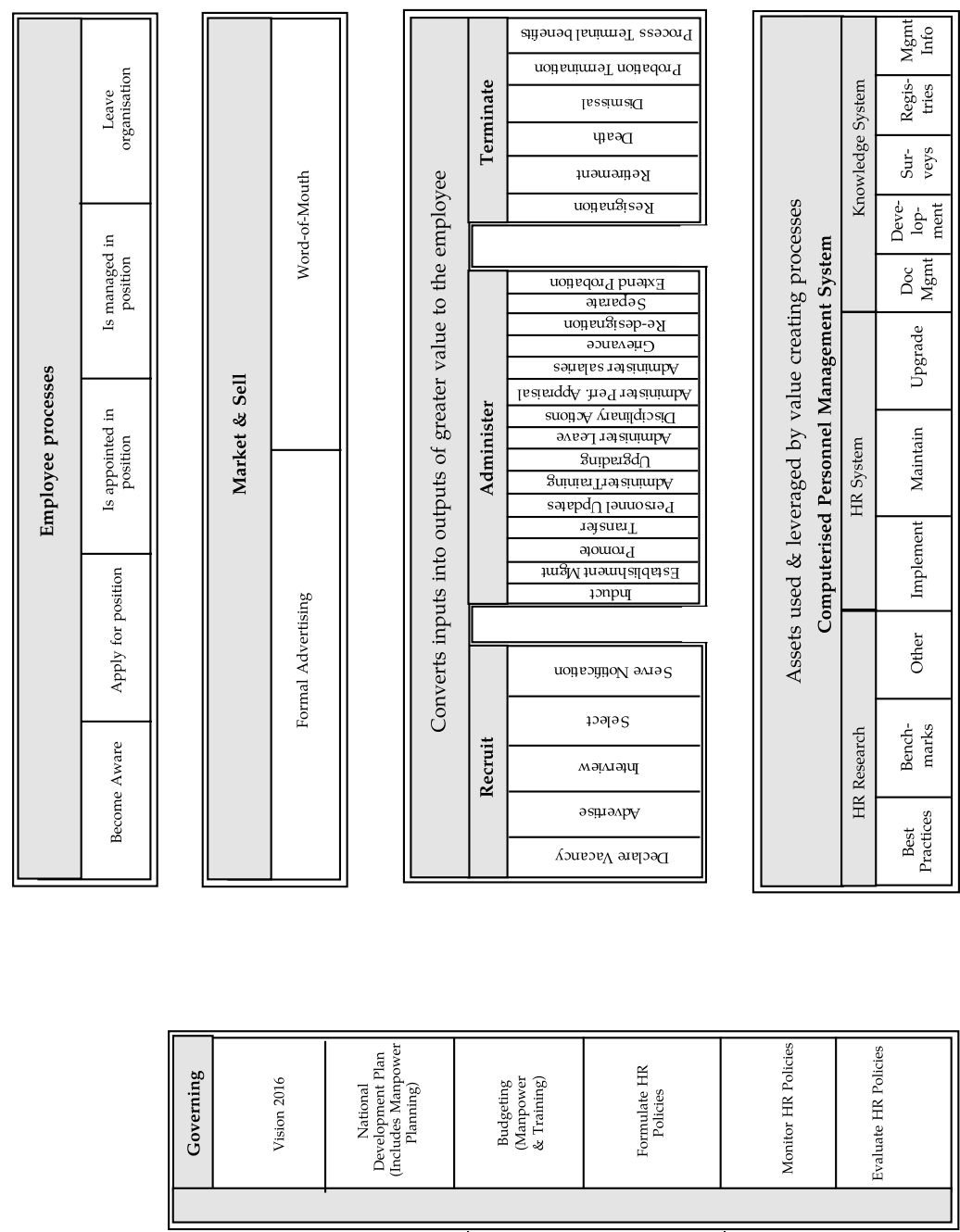

Fig. 9. The high-level Enterprise Model for the HR function (Source: Government of Botswana, 2000) 
assumption that group decisions may not be better than individual decisions. Strategic decisions to form new partnerships or sign a large government contract, for example, were found to be better made only by managers as usual. Directorate experience suggested that sharing the responsibility of taking some types of decisions with large groups of employees not directly involved with decision making on a daily basis simply delayed what could not be delayed, undermining both the employees and management's confidence in participatory management.

There were a number of problems experienced during this phase. These were exacerbated due to a lack of ownership on the part of management. They include such issues as budgeting and funding concerns, the rigid structure of the ministry management, massive staff turnover, poor project ownership, and the absence of a proper system protocol and data availability regime.

Secondly, the analysis and redesign of the human resource processes received a low priority status in the public sector's reform initiatives, and national development plans. For example, by the time this research iteration had begun, the whole set of interrelated activities involved in reviewing the pay structures and performance incentives, from consultants engaged to study the relationships between private sector and public sector remuneration, and the Presidential Commission on salary structures coupled with the implementation difficulties of the performance management system (PMS), had not been addressed by government in at least three years.

The emphasis was on having employees participate in management decisions, rather than in the analysis of how activities were executed and improvements could be attained. Moreover, new ideas for improvement coming from employees covered an overly broad range of subjects, from new designs for promotional material to better wages, leading to a vast amount of contributions coming from staff that had little knowledge about the work of the areas likely to be affected by the ideas. This, and the repetition of ideas, progressively undermined the interest of managers, and consequently employees' motivation to generate new improvement ideas.

\section{Action planning}

The researcher was a consultant with the Management Services' Division (MSD), of the Directorate. MSD is the internal management consultancy arm of government. The researcher was assigned the responsibility of re-engineering the remaining 6 processes, which were not done by the IBM consultants. The project team was expected to tackle a number of problems, both at the local level in the Directorate, and at the level of the human resource departments of client ministries. The researcher was also expected to help coordinate the use of information technology (IT) as an enabler in the implementation of the workflow proposals which came as a result of the human resource process re-engineering. The research iteration was expected to last approximately one year, for the duration of the Directorate's annual performance plan (APP). The researcher and the process owners (Heads of Divisions - Senior Assistant Directors of Directorate, participated in this training exercises and became project champions for the role-out of the CPMS to ministries.

Directorate is a super Department of the ministry of State President. The Directorate is headed by a permanent secretary level Director. The executive management team of the Directorate comprised the Director, two Deputy Directors, and eight Senior Assistant Directors, who are the functional heads of the Divisions of the Department.) They decided that the iteration would begin with a number of training sessions, involving line managers of client ministries, 
in which officers would receive formal hands-on training on HRM techniques based on a methodology developed by the researcher and the IBM Consulting team.

The training sessions were planned so as to include practical HRM exercises, to be done in groups, comprising ten members each. Participating officers from ministries and independent departments were expected to replicate these exercises with real organisational processes after the sessions, using the infinium's (the Human Resources Management Information Systems (HRMIS), personnel actions along with the user manual, of the HRMIS.

\subsection{Recommended workflow points}

The group noted and recommended the following workflow points:

- When a vacancy is declared by the Line Manager, a template in Lotus Notes should be e-mailed, to the Directorate and the Ministry; advising them about the vacancy.

- The Ministry and the Directorate are required to acknowledge the existence of the vacancy to the Line Manager, which should ideally be a response template of Recommendation;

- Directorate and the Line Manager should be notified via Lotus Notes when the vacancy has been actually created in the CPMS;

- If there are recommendations from within the system - all the applicable officers should be notified via Lotus Notes of the vacancy;

- All the job descriptions and advertisements should be kept in a Lotus Notes database and taken from there for electronic approval by the HR ministries;

- The Appointing Board should be notified via Lotus Notes from the system of interview times and dates;

- A database should be set up with rejection letters that are automatically generated from the system;

- The Appointment Board should notify and verify interview times via Lotus Notes;

- The same database in Lotus Notes, should generate the letters of invitation inviting an applicant to come to an interview;

- Notify the Appointment Board that an offer letter has been sent out to the applicant;

- Once the start date is confirmed a form is generated (Casualty Return) and send to the relevant Departments (Accountant General, Directorate, Auditor General, HRM ministries);

- Casualty Return should be triggered by the CPMS, and filled in, in a softcopy format. This should then trigger an e-mail (asynchronously), to be sent to the appropriate parties; and

- Once the employee has actually started his/her duties, the Ministry should be formally notified via e-mail (Lotus Notes).

The researcher and the project team, in diagnosing the problem and the service delivery requirements of the decentralised personnel system, decided to develop an interactive WMS using Lotus Workflow release 3.0. This application was selected because the Directorate was using 'Lotus Notes' and 'Domino Doc', already. Lotus Workflow 3 is one of the product group from the Lotus Corporation groupware solution suite. This KM group was expected to complete the analysis and redesign of each HRM business processes within four to six weeks. After that, a proposal should be generated and implemented, under the coordination of the group leader, who would then prepare a report for approval by Government. 


\section{Action taking}

Seven training sessions were held over a two-week period. These sessions involved all HR managers and officers, lasted one day each, and were conducted by the researcher.

\subsection{Core KM groups}

The core KM groups were tasked to review the following processes:

1. Recruitment, and

2. Personnel Administration.

The evaluation had earlier on, set out how these processes fit within the overall structure of the Directorate. This analysis is set out in section ??: List of core processes, and present the six process maps for the Recruitment process, in section ?? [cf. ??]. These processes are also relevant to how these processes translate into the Directorate Policy Databases. The remaining processes were completed within the specified time, and successfully implemented.

Three high-level KM groups were formed involving the Director and the two Deputy Directors. All three groups had 10 to 14 members, were led by the Deputy Director, or the Senior Assistant Director, and facilitated by the researcher (The members were of similar seniority in the three groups). These groups targeted three main core processes at Directorate: (a) Recruitment process; (b) Personnel Administration, and (c) Policy Database.

The KM group working on the recruitment process made a number of recommendations which were implemented by management within six months of those recommendations being made. The main recommendations are indicted in paragraph 6.1 for the recruitment process. The group also felt that the unit responsible for managing the technical infrastructure of the CPMS should be elevated to the status of a Division with the Directorate structure. This was done within the same time period, as is evidenced by the Functional Structure in Figure ?? The Directorate and HRM ministries were encouraged to use the process maps as templates for carrying out any personnel action. They were also asked to use the CPMS network, and the LotusNotes groupware system whenever they must carry out any personnel action.

Although a number of technical problems were reported by Line managers, during the implementation phase of the CPMS, in general, the system, (the computerised Policy database, and the Infinium HRM applications) were running on the Directorate - Ministry intranet seamlessly, and users of the system, in general, reported significant efficiency gains in their respective local processes (Line ministries) due to the resulting decentralisation of access to data relevant to their activities/personnel actions.

In line with this development, the Directorate implemented version 5, of the Lotus Notes, groupware system, in order to provide greater functionality to users. This email system was linked seamlessly in an integrated suite of tools with the Domino Docs, a database application, which is a sister product of Lotus Notes. This was the kernel on which the Policy Database was built.

The email system (ES) was used as a vehicle to conduct personnel actions. The ES was widely accepted by all the process owners. There were much concerns about issues of confidentially and security in the use of officers personal information, and the protection of the personnel record and data of the Directorate. There were no observed or reported resistance or reluctance, in using the ES for the processing of personnel actions. The researcher surmised this to be due in part to the prior experience officers have in the usage of ES for interaction on a personal basis with family, friends and colleagues. The use of the ES for facilitating KM group work and BPI for the purposes of improving the workflow interactions were implemented for all the 14 processes which were proposed by the consultant. 


\subsection{Local KM groups}

The researcher recommended the use of ministry specific KM groups, using the principles of WITS to target processes cutting across only a few departments within the Ministry. This was the reason for calling them "local" KM groups. One of the rationales for these groups was to improve the ownership of the changes, which were introduced in the processes. These groups had very short-term projects. Some of them lasted only for a few weeks to a month; while others only for a few days. The researcher found that this short-term group duration were particularly linked to a narrow target process scope. Also, that the shortest groups being those targeting very localised processes at the departmental and divisional level. Local WITS groups were led by management as well as line staff.

In the case of Directorate, which was the agency responsible for implementing the PMS in the Public Service, local KM groups abound. There was a long tradition of WITS projects and usage within this agency. So, there was no resistance to the setting up of local KM groups - teams. About seven months after the research iteration had begun four KM groups had completed their work. These groups met exclusively face-to-face, as the ES was unavailable at that stage. As the Directorate had 50 management level staff working in a campus environment, and considering that, a group would last on average of 4 weeks, the Directorate's maximum WITS group capacity was approximately of 4 five-member groups at a time. Some of the groups recommend very impressive alternatives to some of the Directorate processes, while others concentrate on short-term problems. This apparent tendency of some groups to focus on problems rather than on underlying processes has also been pointed out by previous research on both gradual and radical KM groups/community of practice interaction, and occurred in spite of the one-day training sessions previously mentioned.

Some of the Directorate's employees who did not take part in any of the KM groups, reported as one of the reasons for non-participation as being the inability to attend KM group meetings because they were engaged in external activities (e.g. meeting with a client) during scheduled group meetings. Since all the Directorate staff had access to the intranet - the GDN, this problem called for the introduction of the ES prototype developed by the researcher as a tool to allow KM group members to interact from their own computers at different times. This prototype was built on the Lotus Notes infrastructure. Each KM group was assigned a group mailbox upon its creation. KM group mailbox topics were suggestive of the business process under consideration, and held postings from group members' related to different stages of the KM methodology (i.e. process definition, analysis, and redesign). Some KM group mailboxes allowed public access within the organisation to group postings so other public officers could participate in the ongoing discussions. However, some of the KM group mailboxes had restricted access to group members, whenever the discussion was perceived as addressing confidential issues (e.g. possible dismissals as a result of process changes, terminal benefits, termination, etc.).

In addition, a number of public mailboxes were created and gradually populated with information regarding the core business processes of the HRM policies and regulations. This information was previously held in the conventional paper-based "General Orders," and other policy document, such as "savingram" ${ }^{6}$. These mailboxes also contained some regularly updated postings with information about efficiency, PMS outcomes, and service delivery, and ministries and clients complaints for each business process. Employees were instructed

${ }^{6}$ SAVINGRAM - A circular/memorandum document, which provides information on policy/regulation issues that subsequently, becomes part of the "General Order". 
about how to use the Lotus Notes system (ES) to support KM group communication and retrieval of previously posted information, and were encouraged to use the ES as much as possible. None of the local WITS was directly facilitated by the researcher, as was the case of the core KM groups. The reason for this was that the researcher's support was restricted to troubleshooting and orientation meetings with other group facilitators. This means that the researcher's facilitation of local KM groups was indirect.

\section{Evaluating}

In this stage of the AR iteration, one observed a number of patterns evolving into practical learning opportunities. This was against the basic action research routine advocated by Stringer (1999:19). This 'road map', is set out below, in Figure ??, and Table ??. These were related to both face-to face and the ES supported KM groups. The patterns observe in face-to-face discussions related only to the core KM groups, and are summarised in the next three sub-sections [cf. 8].

The pattern observed in the ES-supported KM groups relate to apparent ES-support challenges, and effects on the groups' effectiveness and relevance of the process emerging as a result of these collaborative efforts.

\section{Conclusion}

In this chapter, the first iteration of the AR cycle, was described, which were carried out over a period of approximately one year at Directorate, a Public Administration department, in the Republic of Botswana. At most thirty six public officers were directly involved in this AR iteration. They were all trained based on a methodology developed by the researcher on how to conduct, and participate in KM groups.

With our field research study of KM systems and a literature study of KM research as a basis, we draw four main conclusions:

1. Evolution, which refers to the process in which organisations and their information systems change over time, is an important dimension of KM system implementation and use.

2. Managing the evolution of KM systems on an ad hoc basis and treating them as standalone systems can lead to unnecessary complexity and KM systems failures. The evolution of KM systems needs to be managed by deliberately managing both the systems within the organisation and the organisational change process from a long-term perspective.

3. The KM research has paid little attention to the evolution of KM systems. Limited support and guidelines for managing KM systems' evolution are available in the mainstream KM research literature. Consequently, this is an important issue to add to the KM research discourse. The predominantly design oriented KM research needs to be extended by more implementation and management oriented studies.

4. The implementation of a portal, such as that of the proposed KM-BI model [Fig. 3], will facilitate this process, with the ultimate development of more robust content management systems for integrated knowledge networks for the evolution of innovation and business intelligence through the harnessing of intellectual capital.

Based on this research, it is clear that knowledge management plays a significant role in the liberation of intellectual capital. 


\subsection{Future research direction}

This section summarizes ideas for potential future work, as it relates to the design of a KM system, for the deployment of BI. This list does not include minor improvements or cosmetic changes that are in the implications of implementation of the KM-BI framework.

Therefore, further research may proved valuable, in investigating the potential role of the evolution of knowledge management in knowledge systems, and how the value of intellectual capital can be leveraged to maximized the use of knowledge systems in organisational processes, and to ensure a more efficient and effective liberation of intellectual capital processes and flows.

Allied to the foregoing, impact studies in this area maybe extremely valuable, especially in organisations that have distinct knowledge management systems oriented programs. It is important for knowledge management professionals to understand the systemic relationship between the concepts and the value that can be generated in respect of creating and maintaining sustainable competitive advantage for organisations and naturing, and liberating the natural evolution of intellectual capital.

Ideas for potential future work, as it relates to the design of a KM system, for the deployment of BI are summarized. This list does not include minor improvements or cosmetic changes that are implicit in an organization's implementation of their KM-BI framework.

\subsection{Future work on a learning-oriented KM system}

The literature called for the information systems (IS) field to begin to develop theory based on endogenous paradigms rather than based on other disciplines. The learning-oriented component (OL) of one's model for KM strategy, deals with IS, and as such impacts on the use of the IT infrastructure, as it relates to groupware technologies to aid OL.

There is a need, however, to use a systematic approach to the implementation of this IT infrastructure, which would enable the conceptualize of a robust IS based on expert systems theory. This research has suggested how a KM system may be specified by proposing a high-level casual model of latent factors which impact the implementation of KM practices in an organisational milieu. The portal in the KM-BI model requires the development of the conceptual heuristics so as to operationalise the model. This therefore, requires the testing of individual components [BI, AG, SC, Ol, and $\mathrm{HK}$ ] validation, where appropriate when applying management theories at the implementation process level.

This work involves the use of systems theory, at a design level, to conceptualize both a learning-oriented, and strategy-oriented KM system.

The literature addressed both the design product and the design process. This research presents the design product in our KM-BI model (the conceptualized learning-oriented and the portal components, of the KM-BI system) and portions of the design process (the components). The method of design for the other potential components identified as a result of this research is the conceptualization of methods to achieve other meta-requirements, such as the use of the IT instrastructure. Such work would be analogous to the normalization procedure of a design method that achieves the goal of reducing certain anomalies in a database. Each of the components identified in this research has the ability to achieve the meta-design for our hypothesized KM-BI system.

The findings in this research offer a number of approaches firms may use to implement their $\mathrm{KM}$ projects. The underlying dialogue is that managers need a corporate-wide strategy to implement their KM practices. The researcher discussed throughout this work, and intimated that any successful BI oriented strategy should have the following components:

1. Definition of the system to be assessed; 
2. Identification of relevant stakeholders and their expectations;

3. Definition of the knowledge vision;

4. Deduction of factors of influence and use-and-effect patterns;

5. Identification of the most important drivers;

6. Prioritisation of the impact of the drivers on the expectations of the stakeholders, and

7. Development of an action plan.

These components are distilled from the results of the research. However, the approaches firms may use in implementing KM strategies, by the supported of AG systems have been fully explored. Some of these are summarised next.

- Use information flow and knowledge transfer to improve the competitive advantage and enhanced BI, of the firm through the use of innovative applications of tangible and intangible resources.

- Use new and emerging technologies to improve CA and enhanced BI, of the firm through the use of innovative applications of tangible and intangible technological resources.

- The technological effects of the organizational and environmental evolution needs to be validated with further research on contextualising effects on KM effectiveness. This would include such dimensions as trust and management (leadership) support. The related metrics need to be developed so as to validate the groupware-supported social facilitation factors, which were found in the group domain of the study.

- Understand the impact of organizational learning on information flow, knowledge transfer and new and emerging technologies, through the development of a systematic design model, which our KM-BI framework sought to initiate.

They are therefore constraining their firms from leveraging the BI which could be achieved through the proper use of the technological infrastructure which is a requisite of KM deployment. The observed failure to harness the full potential of the technological infrastructure goes to the heart of the difficulty firms have in selling KM as a management technique to their employees. Technology has changed the way many firms do business globally. In most cases, it has improved their business, though there remain some areas where much improvements may arguably be made. The study found, and ascribe to the belief that the management of technology, has not added value to many organisations' BI.

Our proposed KM-BI model, one believes should afford firms the opportunity to have immediate access to vast stores of processed, timely and relevant knowledge with which they can make decisions. In fact the study found that much of the technology, although new and has been implemented as organizations have begun to experiment with new ways of using it. If a sound business strategy is crafted, then all organisations need to do, when they implement the necessary technology, is to populate it with data so as to make it worth using and to add real benefit to their bottom-line. This in turn means that organisations must focus on keeping the information up-to-date on an on-going basis, and develop a programme of removing out-of-date information and committing resources to this task. The researcher recommend that, in order to obtain the full benefits, organisations need to take a fresh look at the available technology from a KM perspective to realize the potential, in aiding in the liberation of intellectual capital.

Given that the constructs and findings of this study lend support to the validity of our KM-BI framework, a logical next step would be to develop and test more complex theoretical models. 


\section{References}

Adams, G. \& Lamont, B. (2003). Knowledge management systems and developing sustainable competitive advantage, Journal of Knowledge Management 7(2): pp. 142-54.

Baddi, A. \& Sharif, A. (2003). Information management and knowledge integration for enterprise innovation, Logistics Information Management 16(2): pp. 145-55.

Brown, J. S. \& Duguid, P. (1998). Organizing knowledge., California Management Review 40(3): $90-111$.

URL: http://0-search.ebscohost.com.library.vut.ac.za/login.aspx?direct=trueEdb=buhEAN $=738859 \mathcal{E}$ site $=$ bsi-live

Buytaert, D. (n.d.). Core drupal.

Campbell, H. (2005). A study of knowledge management strategies as enabled by the support of asynchronous groupware systems, PhD thesis, University of South Africa, Pretoria, South Africa. Also available at University of South Africa, Main Library. URL: http://uir.unisa.ac.za/handle/10500/2406? show=full

Campbell, H. M. (2009). Linking knowledge management to business intelligence and organisational performance, SAIIE, p. 18.

Cardinal, L., Allessandri, T. \& Turner, S. (2003). Knowledge codifiability, resources, and science based innovation, Journal of Knowledge Management 5(2): pp. 195 - 204.

Cavusgil, S., Calantone, R. \& Zhao, Y. (2003). Tacit knowledge transfer and firm innovation capability, Journal of Business \& Industrial Marketing 18(1): pp. 6-21.

Chen, J., Zhaohui, Z. \& Xie, H. (2004). Measuring intellectual capital, Journal of Intellectual Capital 5(1): pp. $195-212$.

Darroch, J. \& McNaughton, R. (2002). Examining the link between knowledge management practices and types of innovation, Journal of Intellectual Capital 3(3): pp. $210-22$.

Davenport, T. H. \& Prusak, L. (2000). Working Knowledge - How Organizations Manage What they Know, Harvard Business School Press, Boston.

Day, D. \& Tate, B. (2006). Continuous learning: Why is it still an issue, in F. D. e. in Francis J. Yammarino (ed.), Multi-Level Issues in Social Systems (Research in Multi Level Issues, Emerald Group Research Limited, pp. $173-188$.

du Plessis, M. (2007). The role of organizational knowledge management in innovation, Journal of Knowledge Management 11(4): pp. 20-29.

Eftekharzadeh, R. (2008). Knowledge management implementation in developing countries: An experimental study., Review of Business 28(3): $44-58$.

URL: http://0-search.ebscohost.com.library.vut.ac.za/login.aspx?direct=trueEdb=buhEAN $=34757419 \mathcal{E}$ site $=$ bsi-live

Gous, J. \& Schutte, C. (2009). Using knowledge networks to support innovation, SAIIE, p. 18.

Hislop, D. (2005). Knowledge Management in organizations - a critical introduction, Oxford University Press, New York.

Majchrzak, A., Cooper, L. P. \& Neece, O. E. (2004). Knowledge reuse for innovation, Management Science 50(2): pp. 174-188.

URL: http://www.jstor.org/stable/30046057

Martin, W. J. (2004). Demonstrating knowledge value: a broader perspective on metrics, Journal of Intellectual Capital 5(1): 77-79.

Nonaka, I. \& Nishiguchi, T. (2001). Knowledge Emergence, Oxford University Press, New York.

Nonaka, I. \& Takeuchi, H. (1995). The Knowledge Creating Company, Oxford University Press, New York. 
Pyka, A. (2002). Innovation networks in economics: from the incentive-based to the knowledge based approaches, European Journal of Innovation Managementt 5(3): pp. 142-54.

Richard C. Hicks, Ronald Daltero, S. D. G. (2007). A metaphor for knowledge management: explicit islands in a tacit sea, Journal of Knowledge Management 11: 5- 16.

Schutte, C. S. L. \& Preez, N. D. D. (2008). Knowledge networks for managing innovation projects, PICMET.

Seufert, . A., von Krogh, G. \& Bach, A. (1999). Towards knowledge networking, Journal of Knowledge Management 3: 10.

Sveiby, K. E. \& Simons, R. (2002). Collaborative Climate and Effectiveness of Knowledge Work- An Empirical Study,, Journal of Knowledge Management 6(5): 420-433.

van der Aalst, . W. M. \& Kumar, A. K. (2001). A reference model for team-enabled workflow management systems, Data \& Knowledge Engineering 38: 28.

von Krogh, G., Ichijo, K. \& Nonaka, I. (2000). Knowledge Creation - How to unlock the mystery of tacit knowledge and release the power of innovation., Oxford University Press, New York. 


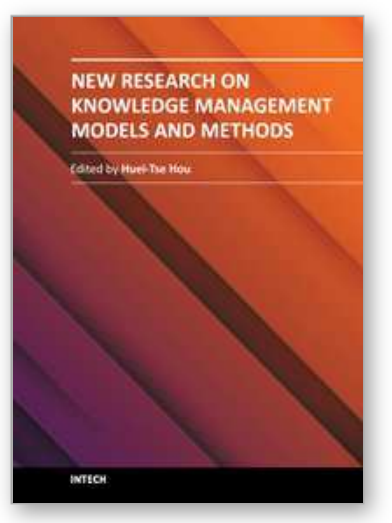

\author{
New Research on Knowledge Management Models and Methods \\ Edited by Prof. Huei Tse Hou
}

ISBN 978-953-51-0190-1

Hard cover, 426 pages

Publisher InTech

Published online 23, March, 2012

Published in print edition March, 2012

Due to the development of mobile and Web 2.0 technology, knowledge transfer, storage and retrieval have become much more rapid. In recent years, there have been more and more new and interesting findings in the research field of knowledge management. This book aims to introduce readers to the recent research topics, it is titled "New Research on Knowledge Management Models and Methods" and includes 19 chapters. Its focus is on the exploration of methods and models, covering the innovations of all knowledge management models and methods as well as deeper discussion. It is expected that this book provides relevant information about new research trends in comprehensive and novel knowledge management studies, and that it serves as an important resource for researchers, teachers and students, and for the development of practices in the knowledge management field.

\title{
How to reference
}

In order to correctly reference this scholarly work, feel free to copy and paste the following:

Harold M. Campbell (2012). The Liberation of Intellectual Capital Through the Natural Evolution of Knowledge Management Systems, New Research on Knowledge Management Models and Methods, Prof. Huei Tse Hou (Ed.), ISBN: 978-953-51-0190-1, InTech, Available from: http://www.intechopen.com/books/new-research-onknowledge-management-models-and-methods/the-liberation-of-intellectual-capital-through-the-naturalevoluion-of-knowledge-management-systems

\section{INTECH}

open science | open minds

\section{InTech Europe}

University Campus STeP Ri

Slavka Krautzeka 83/A

51000 Rijeka, Croatia

Phone: +385 (51) 770447

Fax: +385 (51) 686166

www.intechopen.com

\section{InTech China}

Unit 405, Office Block, Hotel Equatorial Shanghai

No.65, Yan An Road (West), Shanghai, 200040, China

中国上海市延安西路65号上海国际贵都大饭店办公楼 405 单元

Phone: +86-21-62489820

Fax: $+86-21-62489821$ 
(C) 2012 The Author(s). Licensee IntechOpen. This is an open access article distributed under the terms of the Creative Commons Attribution 3.0 License, which permits unrestricted use, distribution, and reproduction in any medium, provided the original work is properly cited. 